\title{
Efficacy of Curcumin in Reducing Risk of Cardiovascular Disease in High Fat Diet-Fed Rats
}

\author{
El-Sayed M El-Habibi' ${ }^{*}$, Azza M El-Wakf ${ }^{1}$ and Abdullah Mogall²
}

${ }^{1}$ Faculty of Science, Mansoura University, Mansoura, Egypt

${ }^{2}$ Faculty of Education, Adan University, Adan, Yemen

\begin{abstract}
This study aimed to explore mechanisms connecting obesity with incidence of cardiovascular disease (CVD) based on the changes in inflammatory response and hematological system. Also, to evaluate the role of curcumin in these changes. Obesity was induced by feeding male rats high fat diet (HFD) daily for three months, whereas curcumin $(20 \mathrm{mg} / \mathrm{kg} \mathrm{b.wt})$ was given orally for the same period. Induction of obesity caused significant increase in the body weight gain with elevation in the levels of total lipids, total cholesterol and triglycerides in serum, aorta and heart. Shifts toward high inflammatory response, as evidenced by increased serum levels of tumor necrosis factoralpha (TNF- $\alpha$ ) and C-reactive protein (CRP) were also observed. This goes with further elevation in total leucocytes, monocytes and lymphocytes, accompanied by decreased nitric oxide (NO) level in serum, aorta and cardiac tissue of the HFD- group. A significant reduction in RBCs count, $\mathrm{Hb}$ content, $\mathrm{MCV}$ and $\mathrm{MCHC} \%$, with elevation in the platelet count and fibrinogen content were also recorded. However, curcumin administration to HFD- fed rats seemed to reduce the increase in body weight and to alleviate all the above mentioned changes. Thus, curcumin could serve as therapeutic agent for protecting against HFD-related CVD.
\end{abstract}

Keywords: Obesity; Curcumin; Cardiovascular disease; Inflammatory response; Hematological system

\section{Introduction}

Obesity is one of the major causes for incidence of cardiovascular disease (CVD) [1] which could be a result of hyperlipidemia, impaired glucose tolerance and hormonal imbalance [2]. However, recent research has indicated that CVD is probably begins and accelerated by other mechanisms potentiated through obesity, such as inflammation [3]. There is evidence that inflammation is the link between obesity and the related cardiovascular disorders. It was also demonstrated that obesity is a chronic inflammatory condition characterized by accumulation of macrophages in adipose tissue and liver, with increased release of inflammatory cytokines especially tumor necrosis factoralpha (TNF- $\alpha$ ) from these macrophages [4]. Additionally, it was also reported that obesity is associated by elevated inflammatory markers such as erythrocyte sedimentation rate (ESR) and C-reactive protein (CRP) which are correlated with other CVD risk factors, including central distribution of body fat, high blood pressure, hyperglycemia and dyslipidemia [5]

Alterations in the hematological system have also considered to play crucial role in obesity-related CVD [6]. The most probable alteration include increased platelet aggregation and thrombus formation [7]. An increased WBCs [8] with reduced RBCs count [9] may also serve as contributing factors. Currently, much research has focused on the use of plant products, such as curcuminin healing different ailments. Curcumin is a natural product derived from the rhizomatous plant turmeric, which is widely used as spice and coloring agent [10]. Also, curcumin is commonly used in traditional medicine as an anti-inflammant. It has been demonstrated to lower the release of proinflammatory eicosanoids and to alleviate the swelling, morning stiffness, and other symptoms in arthritic patients [11]. Orally administered curcumin also lowered carrageenan-induced acute inflammation in rats [12]. In addition, curcumin has shown to inhibit angiogenesis in adipose tissue [13] and to protect against atherosclerosis and platelet aggregation [14]. Keeping into consideration the beneficial role of curcumin, the present study was designed to investigate if the use of this dietary spice would be effective in reducing incidence of CVD in HFD-fed male rats.

\section{Materials and Methods}

\section{Experimental animals}

This study was performed on male albino rats of Wistar strain, initially weighing $175 \pm 5 \mathrm{~g}$. Rats were obtained from the Institute of Ophthalmic Disease Research, Cairo. Egypt. They were housed in stainless steel cages at a well ventilated animal house. Rats were permitted adequate standard diet and given water ad libitum for one week of acclimatization period prior to the experimental work.

\section{Chemicals}

Curcumin [1.7-bis(4-hydroxy-3-methoxyphenyl)-1,6-heptadiene3,5dione] the active constituent of the dietary spice turmeric was purchased from El-gomhoriaCompany for Chemicals, Mansoura, Egypt. All other reagents were of analytical grade and were purchased from local standard suppliers.

\section{Research design}

After one week of acclimatization, rats were randomly divided into five equal groups. The first was considered as control group, in which rats received normal laboratory diet (NLD) without supplementation. The second group was fed NLD and received 5\% DMSO orally as

*Corresponding author: El-Sayed M El-Habibi, Faculty of Science, Mansoura University, Mansoura, Egypt, E-mail: eelhabibi555@yahoo.com

Received May 08, 2013; Accepted July 08, 2013; Published July 10, 2013

Citation: El-Habibi ESM, El-Wakf AM, Mogall A (2013) Efficacy of Curcumin in Reducing Risk of Cardiovascular Disease in High Fat Diet-Fed Rats. J Bioanal Biomed 5: 066-070. doi:10.4172/1948-593X.1000082

Copyright: (C) 2013 El-Habibi ESM, et al. This is an open-access article distributed under the terms of the Creative Commons Attribution License, which permits unrestricted use, distribution, and reproduction in any medium, provided the original author and source are credited. 
vehicle with gastric tube at a dose $0.1 \mathrm{ml} / 100 \mathrm{~g}$ b.wt. In the third group, rats were received curcumin orally at dose of $20 \mathrm{mg} / \mathrm{kg}$ b.wt dissolved in $5 \%$ DMSO. Rats of the fourth group were fed on high fat diet (HFD) consisted of NLD in powder form mixed with melted animal abdominal fat (30\%) and extra pure cholesterol (2\%) [15], while rats of the fifth group were fed HFD and received curcumin orally at the same way and dose as described in the above groups. Rats administrated NLD and HFD daily for three months, while DMSO and curcumin were given every alternate day [16] for the same period. Care and use of the animals were conducted under supervision of the Animal Care Committee of Mansura University, Egypt.

\section{Samples collection}

At the end of the experimental period, all rats were fasted overnight. At 8.00 in the morning, animals were weighed and sacrificed under ether anesthesia. Two blood samples were collected from each rat. The first blood sample was taken on EDTA as anticoagulant for determination of hematological parameters. The second blood sample was collected to obtain serum by centrifugation at $855 \mathrm{~g}$ for 10 minutes. Sera were kept at $-20^{\circ} \mathrm{C}$ for biochemical analysis. Immediately after collecting blood, the animals were dissected. heart, and aorta from each rat were removed, cleaned with saline solution $(0.9 \%)$ and weighed. Samples of aorta and heart were then homogenized and the homogenate was kept frozen at $-20^{\circ} \mathrm{C}$ until being analyzed.

\section{Biochemical analysis}

Total lipids (TLs) [17], total cholesterol (TC) [18], triglycerides (TGs) [19], C-reactive protein (CRP) [20] and nitric oxide (NO) [21] were estimated using kits supplied by Biodiagnostic Co., Mansoura, Egypt.

\section{Inflammatory and hematologic analysis}

Serum tumor necrosis factor-alpha (TNF- $\alpha$ ) was measured, using ELIZA technique, according to [22]. Determination of fibrinogen was carried out using Multifibren - U - Kit, as described by [23]. Red blood cells (RBCs), platelets (PLts) and total white blood cells (WBCs) count were measured by hemocytometer neubauer slide, while differential count of WBCs was determined by Leishman's stained blood film [24]. Hemoglobin $(\mathrm{Hb})$ content was measured colorimetrically by Randox kits according to [25]. Mean corpuscular volume (MCV) and mean corpuscular hemoglobin concentration $(\mathrm{MCHC}) \%$ were calculated using the formulae mentioned by [26].

\section{Statistical analysis}

All data were analyzed by one way analysis of variance (One-way ANOVA) followed by Least Significant Difference (LSD) test, using SPSS statistical package, version 17.00 software. The results were expressed as means \pm S.E and values were considered to be statistically significant at $\mathrm{P}<0.05$ [27].

\section{Results}

Administration of curcumin to normal rats did not produce any significant changes in all tested parameters in comparison to normal rats (Tables 1-3) indicating its nontoxic effect at the applied dose. Feeding rats on high fat diet (HFD) tended to exhibit a significant increase in the body weight gain compared to control rats. On the other hand, administration of curcumin to animals fed on HFD showed significantly reduced body weight compared to obese rats. The present obesity model also showed significant elevation in serum, heart and aorta TLs, TC, and TGs, accompanied by significant reduction of NO level in all tested tissues. Treatment of HFD-fed rats with curcumin significantly decreased various lipid parameters, while an elevation in NO levels in serum, aorta and heart was also recorded compared to non-treated HFD-group (Table 1).

The present data also showed significantly increased serum CRP and TNF- $\alpha$, in the HFD-rats. However; these changes seemed to be alleviated following curcumin treatment (Table 2). Elevations of fibrinogen level, PLts count, as well as WBCs, monocytes and lymphocytes, concomitantly with a reduction in $\mathrm{RBCs}$ count, $\mathrm{Hb}$

\begin{tabular}{|c|c|c|c|c|c|c|}
\hline \multirow{2}{*}{\multicolumn{2}{|c|}{ Tested parameters }} & \multicolumn{5}{|c|}{ Animal groups } \\
\hline & & Control & DMSO & CUR & OB & OB+CUR \\
\hline \multicolumn{2}{|c|}{ Body weight gain (g) } & $118.67 \pm 3.21$ & $117.83 \pm 3.26$ & $117.00 \pm 3.37$ & $176.17 \pm 3.53^{a}$ & $151.67 \pm 1.45 a b c$ \\
\hline \multirow{4}{*}{ 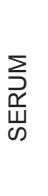 } & TLs (mg/dl) & $439.54 \pm 8.01$ & $438.28 \pm 11.91$ & $433.08 \pm 8.48$ & $873.64 \pm 7.92^{\mathrm{a}}$ & $676.36 \pm 10.83^{\mathrm{ab}}$ \\
\hline & $\mathrm{TC}(\mathrm{mg} / \mathrm{dl})$ & $101.96 \pm 1.75$ & $102.35 \pm 2.45$ & $101.15 \pm 1.86$ & $131.41 \pm 1.76^{\mathrm{a}}$ & $116.86 \pm 3.41^{a b c}$ \\
\hline & $\mathrm{TGs}(\mathrm{mg} / \mathrm{dl})$ & $94.98 \pm 4.07$ & $94.37 \pm 4.83$ & $94.05 \pm 1.90$ & $147.03 \pm 4.87^{\mathrm{a}}$ & $127.29 \pm 4.46^{\mathrm{abc}}$ \\
\hline & $\mathrm{NO}(\mu \mathrm{mol} / \mathrm{L})$ & $68.40 \pm 2.75$ & $68.24 \pm 0.79$ & $68.96 \pm 1.40$ & $45.68 \pm 1.43^{\mathrm{a}}$ & $56.69 \pm 1.79^{a b c}$ \\
\hline \multirow{4}{*}{$\begin{array}{l}\underset{6}{\alpha} \\
\text { ơ } \\
\frac{1}{4}\end{array}$} & $\mathrm{TLs}(\mathrm{mg} / \mathrm{g})$ & $68.74 \pm 1.69$ & $68.56 \pm 1.45$ & $68.09 \pm 1.71$ & $90.44 \pm 1.31^{\mathrm{a}}$ & $81.94 \pm 1.73^{\mathrm{abc}}$ \\
\hline & $\mathrm{TC}(\mathrm{mg} / \mathrm{g})$ & $32.74 \pm 1.32$ & $32.59 \pm 1.67$ & $32.28 \pm 1.54$ & $48.02 \pm 1.21^{\mathrm{a}}$ & $41.28 \pm 0.82^{\mathrm{abc}}$ \\
\hline & $\mathrm{TGs}(\mathrm{mg} / \mathrm{g})$ & $26.56 \pm 2.12$ & $26.38 \pm 1.90$ & $26.09 \pm 1.38$ & $40.59 \pm 1.34^{a}$ & $34.55 \pm 1.87^{\mathrm{ac}}$ \\
\hline & $\mathrm{NO}(\mu \mathrm{mol} / \mathrm{g})$ & $49.43 \pm 1.30$ & $49.11 \pm 0.94$ & $49.96 \pm 1.82$ & $30.81 \pm 2.09^{\mathrm{a}}$ & $42.30 \pm 0.82^{\mathrm{abc}}$ \\
\hline \multirow{4}{*}{$\begin{array}{l}\stackrel{\leftarrow}{\frac{\alpha}{4}} \\
\text { 岌 }\end{array}$} & $\mathrm{TLs}(\mathrm{mg} / \mathrm{g})$ & $63.43 \pm 0.98$ & $63.29 \pm 1.00$ & $63.06 \pm 0.77$ & $80.27 \pm 1.42^{\mathrm{a}}$ & $70.66 \pm 1.82^{\mathrm{abc}}$ \\
\hline & $\mathrm{TC}(\mathrm{mg} / \mathrm{g})$ & $26.97 \pm 1.81$ & $26.72 \pm 0.48$ & $26.41 \pm 1.01$ & $42.61 \pm 2.80^{\mathrm{a}}$ & $35.88 \pm 1.40^{\mathrm{abc}}$ \\
\hline & $\mathrm{TGs}(\mathrm{mg} / \mathrm{g})$ & $25.56 \pm 1.36$ & $25.24 \pm 1.03$ & $25.10 \pm 0.90$ & $35.93 \pm 1.40^{\mathrm{a}}$ & $31.67 \pm 0.95^{\mathrm{ac}}$ \\
\hline & $\mathrm{NO}(\mu \mathrm{mol} / \mathrm{g})$ & $59.29 \pm 0.97$ & $59.18 \pm 1.77$ & $59.92 \pm 1.32$ & $39.50 \pm 1.85^{a}$ & $47.83 \pm 1.54^{\mathrm{abc}}$ \\
\hline OV & \multicolumn{6}{|c|}{$<0.05$} \\
\hline
\end{tabular}

Values are means \pm SE of six animals for each group. DMSO= dimethylsulphoxide, CUR=curcumin, OB=obese. a: significant when compared different groups with control. b: significant when compared $(\mathrm{OB}+\mathrm{CUR})$ with obese.c: significant when compared $(\mathrm{OB}+\mathrm{CUR})$ with curcumin

Table 1: Body weight gain and nitric oxide, as well as serumand tissue lipid profile in control and different treated rat groups. 
content, $\mathrm{MCV}$ and $\mathrm{MCHC} \%$ were also recorded in the HFD-fed rats, in comparison with control group. On the other hand, feeding rats on HFD with curcumin administration caused an ameliorative effect on all these parameters, as evidenced by restoration of the changes in fibrinogen, platelets, WBCs and RBCs count, in addition to the other hematologic indices near to normal values (Table 3).

\section{Discussion}

Obesity is an independent risk factor for developing cardiovascular disease (CVD). Increased accumulation of lipids in the heart and blood vessels may be a major mechanism in this event [28]. However, further research has suggested involvement of other factors, including inflammation. It was indicated that inflammation may be a part of the causal chain that leads to cardiovascular disease [29]. It was also evidenced that obesity is associated with a condition of chronic inflammation, secondary to abnormal production of inflammatory cytokines, such as tumor necrosis factor -alpha (TNF- $\alpha$ ) [4]. TNF- $\alpha$ acts primarily through activating NF-KB which is one of the transcription factors involved in mediating cellular inflammatory response [30]. An increased TNF- $\alpha$ expression and synthesis have been demonstrated with obesity, as being observed by [31] and the current study that showed marked elevation in serum TNF- $\alpha$ level, along with increased body weight gain in the HFD-fed rats.

TNF- $\alpha$ is suggested to play a key role in developing endothelial dysfunction and vascular injury through reducing nitric oxide (NO) production [32]. NO normally functions to maintain vascular homeostasis through a number of physiologic processes, including activation of soluble guanyl cyclase, which produces cyclic guanisine monophosphate (cGMP) being responsible for vasorelaxation [33]. $\mathrm{NO}$ can also act directly on calcium dependent potassium channels, leading to relaxation of vascular smooth muscles (SMCs) [34]. Based on this, the presently observed reduction in NO levels in both, aorta and heart of the obese rats may represent a major factor determining endothelial dysfunction and incidence of CVD.

Further explanation may involve increased C-reactive protein (CRP). An increased CRP was evidenced with obesity [35] confirming the present findings that showed significantly increased CRP level in the obese rats. For this inflammatory marker, previous study has indicated an association between elevated CRP and increased risk of myocardial infarction, peripheral arterial disease and coronary artery disease [36]. Such association seemed to occur primarily through enhancement of WBCs activity which further promotes cardiovascular injury. Thus, CRP may play an indirect role in developing CVD through its association with other risk factors such as WBCs [37]. It was reported that elevated WBCs count is an implication of systemic inflammatory reactions within the body. It involves the production of more white blood cells such as lymphocytes and monocytes. All these cells have their own important role in the inflammatory response [38]. Of importance in this concern is that leukocytes count is not just a marker for CVD, but it actually affects the vessel wall by cascade of inflammatory events that lastly lead to vascular injury. Among them is that activated leukocytes have increased tendency to adhere to vascular endothelium and to cause vascular injury through many stages, including movement of leucocytes, mainly monocytes into the subendothelial space with differentiation of these cells into macrophages and transformation into foam cells [39]. Accordingly, the present finding that HFD-fed

\begin{tabular}{|c|c|c|c|c|c|}
\hline \multirow{2}{*}{ Tested parameters } & \multicolumn{5}{|c|}{ Animal groups } \\
\hline & Control & DMSO & CUR & OB & OB+CUR \\
\hline CRP (mg/L) & $14.83 \pm 0.28$ & $14.33 \pm 0.76$ & $14.00 \pm 0.21$ & $24.42 \pm 0.90^{a}$ & $17.17 \pm 0.54^{\mathrm{bc}}$ \\
\hline TNF- $\alpha$ (pg/mg) & $4.80 \pm 0.12$ & $4.63 \pm 0.11$ & $4.52 \pm 0.15$ & $8.83 \pm 0.39^{a}$ & $6.72 \pm 0.22^{\mathrm{abc}}$ \\
\hline ANOVA & \multicolumn{5}{|c|}{$P<0.05$} \\
\hline
\end{tabular}

Values are means \pm SE of six animals for each group. $\mathrm{DMSO}=$ dimethylsulphoxide, $\mathrm{CUR}=$ curcumin, OB= obese. a: significant when compared different groups with control. b: significant when compared (OB+CUR) with obese.c: significant when compared (OB+CUR) with curcumin.

Table 2: Serum TNF- $\alpha$ and CRP in control and different treated rat groups.

\begin{tabular}{|c|c|c|c|c|c|}
\hline \multirow{2}{*}{ Tested Parameters } & \multicolumn{5}{|c|}{ Animal groups } \\
\hline & Control & DMSO & CUR & OB & OB+CUR \\
\hline $\mathrm{RBCs}\left(\times 10^{3} / \mu \mathrm{L}\right)$ & $6.01 \pm 0.10$ & $6.05 \pm 0.12$ & $6.10 \pm 0.14$ & $5.37 \pm 0.07^{a}$ & $5.82 \pm 0.05^{b}$ \\
\hline $\mathrm{Hb}(\mathrm{g} / \mathrm{dL})$ & $13.73 \pm 0.11$ & $13.60 \pm 0.16$ & $13.55 \pm 0.13$ & $8.68^{a} \pm 0.24$ & $10.98 \pm 0.26^{\mathrm{abc}}$ \\
\hline $\operatorname{MCV}(f L)$ & $68.83 \pm 1.42$ & $68.07 \pm 1.44$ & $67.41 \pm 1.59$ & $60.85 \pm 1.90^{\mathrm{a}}$ & $67.74 \pm 1.66^{b}$ \\
\hline $\mathrm{MCHC} \%$ & $33.30 \pm 0.53$ & $33.09 \pm 0.39$ & $33.04 \pm 0.38$ & $26.64 \pm 0.51^{a}$ & $27.98 \pm 1.04$ ac \\
\hline WBC $\left.\left.\left(\times 10^{3} / \mu \mathrm{L}\right) / \mu \mathrm{L}\right) 3 / \mu \mathrm{L}\right)(\times 103 / \mu \mathrm{L})$ & $5.45 \pm 0.05$ & $5.52 \pm 0.08$ & $5.13 \pm 0.08$ & $6.67 \pm 0.08^{a}$ & $5.47 \pm 0.17^{b}$ \\
\hline Monocytes \% & $6.97 \pm 0.31$ & $6.83 \pm 0.23$ & $6.22 \pm 0.17$ & $8.57 \pm 0.37^{\mathrm{a}}$ & $7.82 \pm 0.54^{c}$ \\
\hline Lymphocytes \% & $45.73 \pm 1.72$ & $45.53 \pm 0.63$ & $45.05 \pm 0.65$ & $56.48 \pm 0.97^{a}$ & $47.27 \pm 0.72^{b}$ \\
\hline $\operatorname{PLts}(\times 103 / \mu L)$ & $453.83 \pm 3.52$ & $453.50 \pm 1.65$ & $453.17 \pm 1.35$ & $562.17 \pm 4.80^{\mathrm{a}}$ & $477.33 \pm 3.57^{\mathrm{abc}}$ \\
\hline Fibrinogen(mg/dl) & 117.834 .04 & 117.331 .76 & 117.174 .42 & $260.826 .54^{a}$ & $212.162 .96 \mathrm{abc}$ \\
\hline ANOVA & \multicolumn{5}{|c|}{$P<0.05$} \\
\hline
\end{tabular}

Values are means $\pm \mathrm{SE}$ of six animals for each group. $\mathrm{DMSO}=$ dimethylsulphoxide, $\mathrm{CUR}=$ curcumin, $\mathrm{OB}=$ obese. a: significant when compared different groups with control. b: significant when compared $(\mathrm{OB}+\mathrm{CUR})$ with obese. c: significant when compared $(\mathrm{OB}+\mathrm{CUR})$ with curcumin.

Table 3: Hematological parameters in control and different treated rat groups. 
rats showed elevated total and differential leukocytes (monocytes and lymphocytes) count may indicate high inflammatory response in this diet-induced obesity model.

An increase in the inflammatory response may enhance activation of leukocytes and endothelial cells, thereby promoting platelet aggregation and thrombus formation [40]. Moreover, increased number and activation of leukocytes and platelets promote formation of leukocyte-platelet aggregates which contribute to pathophysiological processes leading to increased risk for atherosclerotic lesions [8]. Platelets are cells that play a key role in the coagulation process. By adhering to damaged blood vessels, platelets become activated [41] resulting in changes in its shape and aggregation via cross-linking by intact fibrinogen which in turn modulates coagulation process [42]. Thus, elevation in the two hematological parameters, platelets and fibrinogen, as similarly described in the present study may indicate enhanced coagulation and thrombosis with increased tendency for CVD.

Beyond this effect, other hematological parameters, such as RBCs count may exert apparent influence in the genesis of CVD. A number of changes can affect RBCs, leading to reduction in their count which in turn may contribute to the risk of CVD [10]. It was indicated that RBCs are particularly exposed to oxidative hazards because of their specific role as oxygen carriers. Under normal physiologic conditions, there is a balance between production of ROS and their destruction by the endogenous antioxidant defense system [43]. However, the existing state of obesity with elevated lipid profile (TLs, TC,TGs) as seen in the current study and in other research [44] may increase generation of ROS and oxidative stress. This can damage both plasma membrane and cytosolic components, leading to oxidative hemolysis of RBCs and decreased survival of oxidized RBCs in circulation [45]. A finding which may provide an explanation for the present findings of decreased RBCs count and other hematological indices ( $\mathrm{Hb}, \mathrm{MCV}$ and $\mathrm{MCHC} \%)$ in the obese rats. Decreased RBCs may lead to reduced rate of blood flow and oxygen diffusion through the RBCs membranes. This in turn may reduce the aerobic metabolism of glucose and fatty acids, leading to hypoxic state both in heart and endothelial cells, accompanied by cardiovascular injury often associated with obesity [46]. Currently, there is increasing interest in establishing non therapeutic ways for reducing obesity and its related health problems. Curcumin is a natural product derived from the herbal plant turmeric. It is a nontoxic agent having a wide variety of pharmacological activities [47]. In the present study, curcumin administration to HFD-rats succeeded to exert apparent cardiovascular protective action, which seemed to be mediated primary through reducing body weight gain. Besides, curcumin tended to exhibit marked anti-inflammatory properties, as evidenced from the reduction in the inflammatory markers, TNF- $\alpha$ and CRP, in parallel with further reduction in total and differential WBCs count. The antiinflammatory action of curcumin may be exerted through different pathways. First, curcumin has suppressive effect on production of the inflammatory cytokine TNF- $\alpha$, which in turn leads to inhibition of NF-KB being responsible for promoting intracellular inflammation [48]. Additionally, curcumin was reported to lower production of CRP [49] and to cause marked decrease in WBCs count [50], which in all act as potential candidates for reducing enhanced inflammation. Apart from this, curcumin appeared to possess improving action on a number of hematological alterations. Curcumin was found to be effective in protecting RBCs against oxidative damage induced by direct application of $\mathrm{H}_{202}$ [51]. Also it can decrease lipid peroxidation in RBCs membranes by maintaining the activities of antioxidant enzymes, like
SOD and CTA [52]. Previously, it was reported that increased ROS generation as in obesity is a key role for RBCs hemolysis, and reduced RBCs count and that curcumin protection may be mediated through scavenging free radicals and reducing oxidative stress [45]. The present observation that curcumin administration to HFD-rats increased $\mathrm{RBC}$ count and other hemalogical indices ( $\mathrm{Hb}, \mathrm{MCV}, \mathrm{MCHC} \%)$ near to normal values in the HFD rats may thus indicate decreased rate of RBCs hemolysis which in turn may exert protection against cardiovascular injury. In association, curcumin was found to inhibit platelets aggregation, probably through interfering with cytosolic $\mathrm{Ca} 2+$ being responsible for platelets activation and aggregation [53]. Curcumin was reported also to inhibit fibrinogen synthesis and to reduce levels of fibrinogen [54]. As such, the present study showed reduced values of fibrinogen and platelet count when curcumin was administrated to HFD-rats, thus, indicating physiologic response for protecting against thrombosis and risk of CVD [55].

In conclusion, curcumin administration has shown to inhibit HFDrelated inflammation and hematological changes which ultimately prevent development of aorta and cardiac disorders. Curcumin may therefore recommended to be used as a functional food by subjects of expected CVD.

\section{References}

1. Shah A, Mehta N, Reilly MP (2008) Adipose inflammation, insulin resistance, and cardiovascular disease. JPEN J Parenter Enteral Nutr 32: 638-644.

2. Marinou K, Tousoulis D, Antonopoulos AS, Stefanadi E, Stefanadis C (2010) Obesity and cardiovascular disease: from pathophysiology to risk stratification. Int J Cardiol 138: 3-8.

3. Singhal A, Farooqi IS, Cole TJ, O'Rahilly S, Fewtrell M, et al. (2002) Influence of leptin on arterial distensibility: a novel link between obesity and cardiovascular disease? Circulation 106: 1919-1924

4. Dandona P, Aljada A, Chaudhuri A, Mohanty P, Garg R (2005) Metabolic syndrome: a comprehensive perspective based on interactions between obesity, diabetes, and inflammation. Circulation 111: 1448-1454.

5. Canoy D (2008) Distribution of body fat and risk of coronary heart disease in men and women. Curr Opin Cardiol 23: 591-598.

6. DeClercq V, Taylor C, Zahradka P (2008) Adipose tissue: the link between obesity and cardiovascular disease. Cardiovasc Hematol Disord Drug Targets 8: 228-237.

7. Lohsoonthorn V, Jiamjarasrungsi W, Williams MA (2007) Association of Hematological Parameters with Clustered Components of Metabolic Syndrome among Professional and Office Workers in Bangkok. Diabetes Metab Syndr 1 : 143-149.

8. Imano H, Sato S, Kitamura A, Kiyama M, Ohira T, et al. (2007) Leukocyte coun is an independent predictor for risk of acute myocardial infarction in middleaged Japanese men. Atherosclerosis 195: 147-152.

9. Blum A (2009) The possible role of red blood cell microvesicles in atherosclerosis. Eur J Intern Med 20: 101-105

10. El-Wakf AM, Elhabiby EM, El-kholy WM, Abd El-Ghany E (2011) Use of tumeric and curcumin to alleviate adverse reproductive outcomes of water nitrate pollution in male rats. Nat \& Sci 9: 229.

11. Jancinovai V, Perecko T, Nosail R, Kostajlova; D, Bauerova; K, et al. (2009) Decreased activity of neutrophils in the presence of diferuloylmethane (curcumin) involves protein kinase $\mathrm{C}$ inhibition. Eur J Pharmacol 612: 161-166.

12. Joe B, Lokesh BR (1997) Prophylactic and therapeutic effects of n-3 polyunsaturated fatty acids, capsaicin, and curcumin on adjuvant induced arthritis in rats. J Nutr Biochem 8: 397-407.

13. Ejaz A, Wu D, Kwan P, Meydani M (2009) Curcumin inhibits adipogenesis in 3T3-L1 adipocytes and angiogenesis and obesity in C57/BL mice. J Nutr 139 919-925.

14. Shin SK, Ha TY, McGregor RA, Choi MS (2011) Long-term curcumin 
Citation: El-Habibi ESM, El-Wakf AM, Mogall A (2013) Efficacy of Curcumin in Reducing Risk of Cardiovascular Disease in High Fat Diet-Fed Rats. J Bioanal Biomed 5: 066-070. doi:10.4172/1948-593X.1000082

administration protects against atherosclerosis via hepatic regulation of lipoprotein cholesterol metabolism. Mol Nutr Food Res 55: 1829-1840.

15. Gupta S, Kaushik M (2010) Histomorphologicl and hypolipidaemic effects from whole plant of Gymenma Sylvestre in high cafeteria diet-induced obese rat model. J pharm Bio Sci 2: 1-9.

16. Kalpana C, Menon VP (2004) Modulatory effects of curcumin on lipid peroxidation and antioxidant status during nicotine-induced toxicity. Pol $J$ Pharmacol 56: 581-586.

17. Zolliner N, Kisch K (1962) Uber die quantitative Bestimmung von Lipoiden (Mikromethode) mittels der vielen naturlichen Lipoiden (allen bekannten plasmalipoiden) gemeinsamen Sulfophosphovanillin-Reaktion. Exp Med 135: 545-561.

18. Allain CC, Poon LS, Chan CS, Richmond W, Fu PC (1974) Enzymatic determination of total serum cholesterol. Clin Chem 20: 470-475.

19. Fossati $P$, Prencipe $L$ (1982) Serum triglycerides determined colorimetrically with an enzyme that produces hydrogen peroxide. Clin Chem 28: 2077-2080.

20. Peltola H, Saarinen UM, Siimes MA (1983) C-reactive protein in rapid diagnosis and follow-up of bacterial septicemia in children with leukemia. Pediatr Infect Dis 2: $370-373$.

21. Montgomery HA, Dymock JF (1961) The determination of nitrate in water. Analyst 86: 414-416.

22. Aggarwal BB, Kohr WJ, Hass PE, Moffat B, Spencer SA, et al. (1985) Human tumor necrosis factor. Production, purification, and characterization. J Biol Chem 260: 2345-2354.

23. Cooper J, Douglas AS (1991) Fibrinogen level as a predictor or mortality on survivors of myocardial infarction. Fibrinolysis 5: 105-108.

24. Harvey JW (2001) Atlas of veterinary hematology. WB saunders company, Philadelphia P. 41.

25. Haemat BJ (1967) International committee for standarization in hematology. $J$ Clin Pathol 13: 71-72.

26. Dacie JV, Lewis SM (2001) Practical Haematology, 9th edition. Churchill Livingstone, London PP. 633.

27. Snedecor CW, Cochran WC (1980) Statistical Methods. (7thedn). The Stae University Press American, lowa P.593.

28. Balamurugan G, Muralidharan $P$ (2010) Antiobesity effect of Bauhinia variegata bark extract on female rats fed on hypercaloric diet. Bangladesh J Pharmacol 5: 8-12.

29. Wang Z, Nakayama T (2010) Inflammation, a link between obesity and cardiovascular disease. Mediators Inflamm 2010: 535918.

30. Menon VP, Sudheer AR (2007) Antioxidant and anti-inflammatory properties of curcumin. Adv Exp Med Biol 595: 105-125

31. Löfgren $P_{2}$ van Harmelen $V_{2}$ Reynisdottir $S_{2}$ Näslund $E_{2}$ Rydén $M$, et al. (2000) Secretion of tumor necrosis factor-alpha shows a strong relationship to insulinstimulated glucose transport in human adipose tissue. Diabetes 49: 688-692.

32. Zhang JV, Ren PG, Avsian-Kretchmer O, Luo CW, Rauch R, et al. (2005) Obestatin, a peptide encoded by the ghrelin gene, opposes ghrelin's effects on food intake. Science 310: 996-999.

33. Dhir A, Kulkarni SK (2007) Involvement of L-arginine-nitric oxide-cyclic guanosine monophosphate pathway in the antidepressant-like effect of venlafaxine in mice. Prog Neuropsychopharmacol Biol Psychiatry 31: 921-925.

34. Costa RS, Assreuy J (2005) Multiple potassium channels mediate nitric oxideinduced inhibition of rat vascular smooth muscle cell proliferation. Nitric Oxide 13: $145-151$

35. Salmenniemi U, Ruotsalainen E, Pihlajamki J, Vauhkonen I, Kainulainen $\mathrm{S}$, et al. (2004) Multiple abnormalities in glucose and energy metabolism and coordinated changes in levels of adiponectin, cytokines, and adhesion molecules in subjects with metabolic syndrome. Circulation 110: 3842-3848.

36. Ridker PM (2003) Clinical application of C-reactive protein for cardiovascular disease detection and prevention. Circulation 107: 363-369.

37. Kuo HK, Bean JF, Yen CJ, Leveille SG (2006) Linking C-reactive protein to late-life disability in the National Health and Nutrition Examination Survey (NHANES) 1999-2002. J Gerontol A Biol Sci Med Sci 61: 380-387.
38. Antony S, Kuttan R, Kuttan G (1999) Immunomodulatory activity of curcumin Immunol Invest 28: 291-303.

39. Jialal I, Devaraj S, Venugopal SK (2004) C-reactive protein: risk marker or mediator in athero- thrombosis? Hyperten 44: 6-11.

40. Ross R (1999) Atherosclerosis--an inflammatory disease. N Engl J Med 340 115-126.

41. Ni H, Freedman J (2003) Platelets in hemostasis and thrombosis: role of integrins and their ligands. Transfus Apher Sci 28: 257-264.

42. Murugappan S, Shankar H, Kunapuli SP (2004) Platelet receptors for adenine nucleotides and thromboxane A2. Semin Thromb Hemost 30: 411-418.

43. Takenaka Y, Miki M, Yasuda H, Mino M (1991) The effect of alpha-tocophero as an antioxidant on the oxidation of membrane protein thiols induced by free radicals generated in different sites. Arch Biochem Biophys 285: 344-350.

44. Dandona P, Mohanty P, Ghanim H, Aljada A, Browne R, et al. (2001) The suppressive effect of dietary restriction and weight loss in the obese on the generation of reactive oxygen species by leukocytes, lipid peroxidation, and protein carbonylation. J Clin Endocrinol Metab 86: 355-362.

45. Manna C, Galletti P, Cucciolla V, Montedoro G, Zappia V (1999) Olive oil hydroxytyrosol protects human erythrocytes against oxidative damages. J Nutr Biochem 10: 159-165.

46. Cazzola R, Rondanelli M, Russo-Volpe S, Ferrari E, Cestaro B (2004) Decreased membrane fluidity and altered susceptibility to peroxidation and lipid composition in overweight and obese female erythrocytes. J Lipid Res 45: $1846-1851$.

47. Chattopadhyay I, Biswas K, Bandyopadhyay U, Banerjee RK (2004) Turmeric and curcumin: Biological actions and medicinal applications. Current science 87: $44-53$

48. Surh YJ, Chun KS, Cha HH, Han SS, Keum YS, et al. (2001) Molecular mechanisms underlying chemopreventive activities of anti-inflammatory phytochemicals: down-regulation of COX-2 and iNOS through suppression of NF-kappa B activation. Mutat Res 480-481: 243-68.

49. Johnston BD, DeMaster EG (2003) Suppression of nitric oxide oxidation to nitrite by curcumin is due to the sequestration of the reaction intermediate nitrogen dioxide, not nitric oxide. Nitric Oxide 8: 231-234.

50. Das S, Kamarudin TA, Othman F, Ramli ES, Isa NM (2012) Protective effect of curcumin on experimentally induced arthritic rats: detailed histopathological study of the joints and white blood cell count. EXCLI J 11: 226-236.

51. Clemens MR, Waller HD (1987) Lipid peroxidation in erythrocytes. Chem Phys Lipids 45: 251-268

52. Ahmed FN, Naqvi FN, Shafiq F (2006) Lipid peroxidation and serum antioxidant enzymes in patients with type 2 diabetes mellitus. Ann N Y Acad Sci 1084 481-489.

53. Heemskerk JW, Sage SO (1994) Calcium signalling in platelets and other cells Platelets 5: 295-316.

54. Ramirez Boscai A, Soler A, Carrian-Gutiarrez MA, Pamies Mira D, Pardo Zapata J, et al. (2000) An hydroalcoholic extract of Curcuma longa lowers the abnormally high values of human-plasma fibrinogen. Mech Ageing Dev 114: 207-210.

55. Kim M, Kim Y (2010) Hypocholesterolemic effects of curcumin via up-regulation of cholesterol 7a-hydroxylase in rats fed a high fat diet. Nutr Res Pract 4: 191 195. 